Note

\title{
Error analysis in the estimation of coral reef fish numbers from visual surveys
}

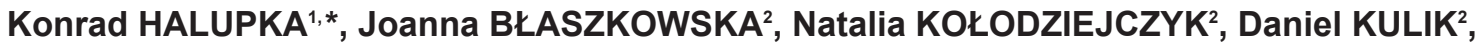 Paweł NOWAK ${ }^{2}$, Ewa PRZEPIÓRKA ${ }^{2}$, and Sonia SIEMIANOWSKA ${ }^{2}$}

${ }^{1}$ Department of Behavioural Ecology, University of Wroclaw, Poland

${ }^{2}$ Student Scientific Society of Ethology, University of Wroclaw, Poland

* Corresponding author: K. Halupka

E-mail: konrad.halupka@uni.wroc.pl

Communicated by Beatriz E. Casareto (Associate Editors-in-Chief)

\begin{abstract}
The study quantifies different sources of error in the visual censuses of 12 fish species on a fringing coral reef. Each species was censused 24 times within a period of four days. We assumed that in this narrow time window, true abundances of species were constant, and that the variation observed in the estimates was due to short-term environmental oscillations, inter-observer differences, and chance events. ANOVA revealed that the environmental variance in four species, inter-observer variance in three species, and chance variance in one species contributed most to the censusing results. In the remaining four species, the variance components were similar in magnitude. We conclude that identifying important sources of error variance, which allows for the informed correction of censusing methods, could increase the precision and comparability of density estimates.
\end{abstract}

Keywords census, transect method, population density estimation

\section{Introduction}

In ecological research examining spatiotemporal patterns in the distribution of animals, comparability of density estimates is essential. The ability to discriminate between two localities containing different numbers of the studied organism depends on the precision of censuses, that is, consistency of estimates (Samoilys and Carlos 2000; McClanahan et al. 2007).

Visual counts are widely used as methods of noninvasive censusing of fish on coral reefs (Jennings and Polunin 1996; McClanahan and Arthur 2001; Emslie et al. 2011). Census data reflect both biologically meaningful variation from spatiotemporal differences in the number of individuals, and "unwanted" variation such as estimation errors due to short-term environmental oscillations, observer bias and chance events (Samoilys and Carlos 2000; Edgar et al. 2004; McClanahan et al. 2007). Here we decompose the variance in the results of censuses carried out using the same method, at the same location and within a short seasonal window, to quantify the proportion of the total variation accounted for by each of these error factors.

\section{Materials and Methods}

The study was carried out between 19 and 24 April 2015 on a Red Sea coral reef located along the south bank 
of a narrow, $600 \mathrm{~m}$ inland bay $(25.206 \mathrm{~N}, 34.810 \mathrm{E})$, close to the town of Marsa Alam (Egypt). The reef has a typical fringing zonation, beginning with a shallow lagoon, a $20^{-}$ $40 \mathrm{~m}$ wide reef flat, and a reef margin with a prominent crest (in sight at low tides) adjoining an almost vertical outer slope. The water at the base of the slope is between 3 and $10 \mathrm{~m}$ deep. Tides are noticeable, with water level changing by about $0.7 \mathrm{~m}$. At the time of research the reef was in good shape, with massive colonies of hard corals and a high diversity of fishes.

The reef begins near the sandy end of the bay, which is frequented by tourists. As a result, the study transect started $50 \mathrm{~m}$ farther, and ran for $220 \mathrm{~m}$ along the reef crest, toward the bay entrance. Although the transect appears linear on the map, observers had to zigzag through channels in the crest to inspect reef-ponds on the shoreward side and coral pinnacles on the seaward side. We used the strip transect method: census-takers were instructed to keep within $5 \mathrm{~m}$ of the crest and maintain a swimming speed allowing for completion of two census replicates (forward and backward transect runs) within 40-60 minutes.

We censused 12 species, all relatively conspicuous and easy to recognize. These included five species from the family Chaetodontidae: the crown butterflyfish (Chaetodon paucifasciatus Ahl, 1861), masked butterflyfish (C. semilarvatus Cuvier, 1831), Red Sea raccoon butterflyfish (C. fasciatus Forsskål, 1775), threadfin butterflyfish (C. auriga Forsskål, 1775), and exquisite butterflyfish (C. austriacus Kossmann and Räuber, 1877). Acanthuridae were represented by three species: the sohal surgeonfish (Acanthurus sohal Forsskål, 1775), yellowtail tang (Zebrasoma xanthurum Blyth, 1852) and orange-spine unicornfish (Naso elegans Rüppell, 1829). Another four families (Pomacanthidae, Balistidae, Labridae, Tetraodontidae) were represented by a single species: the regal angelfish (Pygoplites diacanthus Boddaert, 1772), Picassofish (Rhinecanthus assasi Forsskål, 1775), Klunzinger's wrasse (Thalassoma rueppellii Klunzinger, 1871), and the masked puffer (Arothron diadematus Rüppell, 1829). Pilot censuses revealed a high variation in the body size of T. rueppellii, with numerous smaller individuals; censusing this species was thus standardized using the rule "only fish longer than $10 \mathrm{~cm}$ count".
As part of four one-hour training sessions carried out within two days preceding data collection, observers practiced snorkeling along the transect, identifying fish species and instantaneously recording the results of counts on waterproof slates. During this training phase, observers were encouraged to share and discuss experiences regarding transect topography and species-specific behavioral patterns that might affect fish detectability. During the subsequent data-collection phase, to avoid gradual deflation of between-observer variation in the results, an information embargo was imposed; censusing techniques and results were not discussed, and each observer reported data only to one person, immediately after completing each census.

Censuses were carried out twice daily over the four days following the training phase, once in the morning, between 09.30 and 11.30, and once in the afternoon, between 15.30 and 17.30. During every census, each of the six observers independently tallied three species. Each observer repeated their census twice (forward and backward run), thus delivering two estimates of the given species number. In sum, over the four days a total of 8 censuses were carried out and 288 estimates of fish numbers were obtained ( 8 censuses $\cdot 2$ replicates $\cdot 3$ species $\cdot 6$ observers), with each species censused 24 times ( 6 censuses $\cdot 2$ replicates $\cdot 2$ observers).

We assumed that the number of each species recorded along the transect was, within the four days of data collection, roughly constant and that the variation in the number of individuals observed between censuses (henceforth: environmental variance) was due to shortterm oscillations in environmental conditions affecting fish detectability (censuses were conducted at different times of day, under varying tides, wind speeds, waving, water temperatures, sun exposition, etc.). Another source of error, between-observer variation (henceforth: observer variance), can be caused by differences in observers' skills, swimming speeds and other details of the censusing technique, which we neglected to standardize. Finally, between-replication variation (henceforth: chance variance), that is, differences in the results delivered by the same person in almost identical settings (forward and backward swims along the transect), can be a result of the instantaneous reaction of fishes to waves, predators, 
competitors, their own foraging activities, and social interactions. As the complex, three-dimensional reef structure occludes visibility and both the observer and fishes are mobile, even a small change in the position of an individual fish relative to the observer can affect the census result.

Statistical analysis was carried out using square-root transformed data regarding the number of fish. For each species we calculated descriptive statistics (the mean of 24 estimates and its coefficient of variation, henceforth: $\mathrm{CV}$ ) and then partitioned the total variance in the number of individuals into the three random effect components outlined above: environmental variance, observer variance, and chance variance. We used an ANOVA design comprising two transect runs nested within observers, nested within censuses. Each component of the variance was calculated as a percentage of the total sum of squares. For each species the analysis was bootstrapped 5000 times. Every re-sampling block included 4 surveys (two replicates made at the same time by two observers), thus 24 surveys included 6 re-sampling blocks. The analysis produced median estimates of variance components and their 95\% bootstrap percentile confidence intervals (Fig. 1). Variance components were compared only within same-species blocks, with non-overlapping 95\% confidence intervals employed as a criterion of statistical significance. All statistical analyses were run in $\mathrm{R}$ version 3.2.2 (R Core Team 2015) and the library 'boot' (Davison and Hinkley 1997; Canty and Ripley 2015) used for bootstrapping.

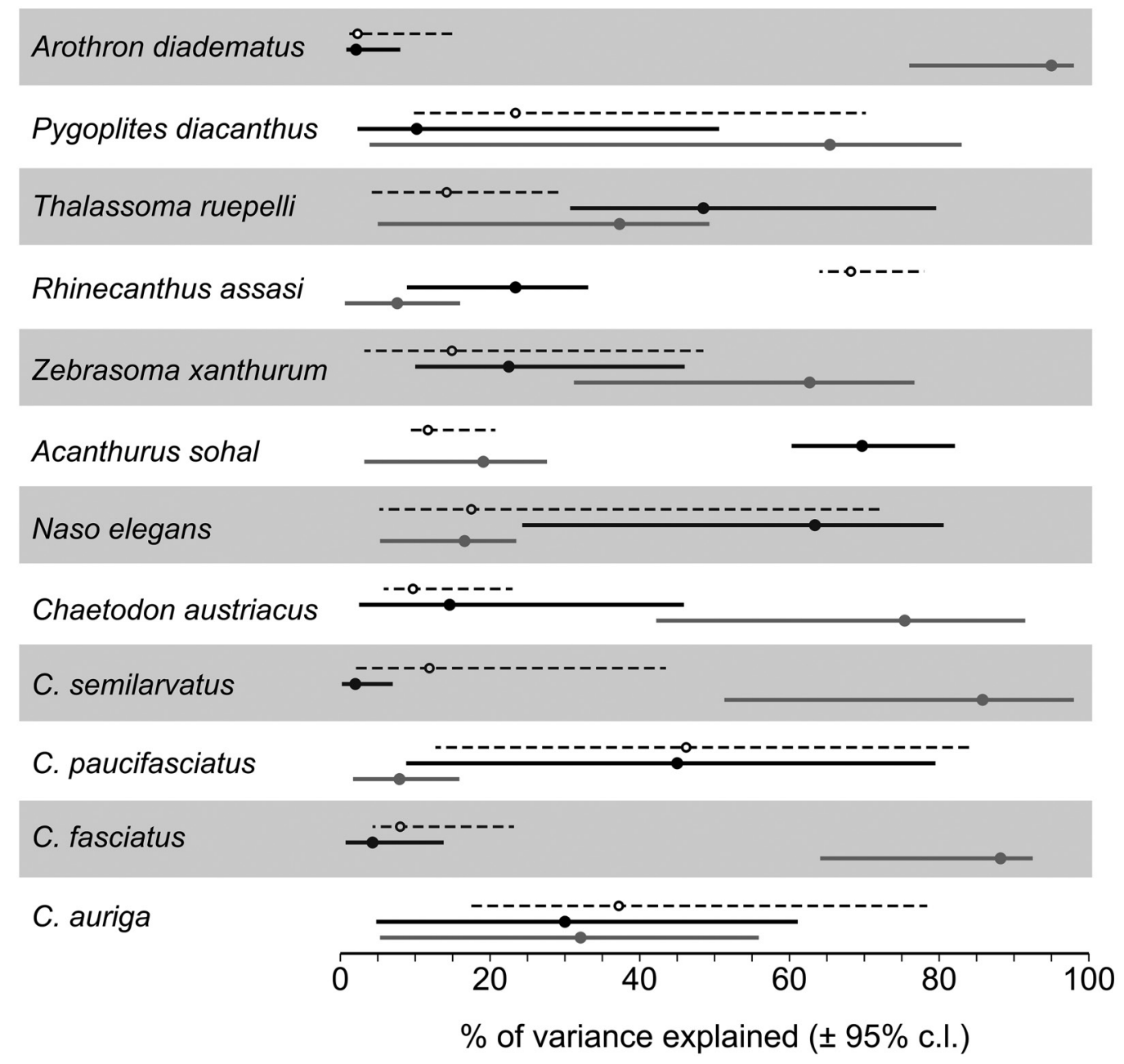

Fig. 1 Percentage of total variance in the census results of 12 fish species, accounted for by environmental variance (gray dots), observer variance (black dots) and chance variance (white dots). Median values and their 95\% bootstrap percentile confidence intervals are presented. 
Table 1 Mean (per $220 \mathrm{~m}$ transect run, N=24) and coefficient of variation of the number of individuals of 12 species of coral reef fishes.

\begin{tabular}{lrr}
\hline Species & Mean & CV \\
\hline Arothron diadematus & 2.71 & 0.950 \\
Pygoplites diacanthus & 4.57 & 0.187 \\
Thalassoma rueppellii & 8.59 & 0.252 \\
Rhinecanthus assasi & 0.18 & 2.513 \\
Zebrasoma xanthurum & 26.84 & 0.064 \\
Acanthurus sohal & 24.85 & 0.139 \\
Naso elegans & 12.54 & 0.091 \\
Chaetodon austriacus & 7.34 & 0.204 \\
C. semilarvatus & 3.14 & 0.768 \\
C. paucifasciatus & 5.33 & 0.352 \\
C. fasciatus & 12.26 & 0.199 \\
C. auriga & 7.34 & 0.204 \\
\hline
\end{tabular}

\section{Results and Discussion}

The mean number of individuals of each species recorded on a single transect run and their respective $\mathrm{CV}$ values are reported in Table 1. CVs ranged from 0.064 to 2.513 and decreased significantly with mean values $\left(\mathrm{r}_{\mathrm{s}}=\right.$ -0.867 , two-tailed $\mathrm{P}<0.001)$. The results of variance partitioning (Fig. 1) suggested that the study species can be divided into four distinct groups: i) those for which environmental variance contributed the most to the results of censusing (A. diadematus, C. austriacus, C. semilarvatus, and $C$. fasciatus), ii) those for which observer variance was the most important component (A. sohal, $T$. rueppellii, and N. elegans), iii) R. assasi, for which chance variance predominated, and iv) all remaining species, for which the three variance components were equally important (P. diacanthus, Z. xanthurum, C. paucifasciatus, and C. auriga).

Keast and Harker (1977) arbitrarily proposed that when comparing census results, $\mathrm{CV}$ values of around 0.1 enable the detection, with sufficient power, of ecologically meaningful differences between transects. An explicit analysis (Plumtre 2000) has shown that a CV of 0.1 allows for the detection of a $30 \%$ difference in the number of censused organisms with $50 \%$ power. Lower precision causes a dramatic decline in resolution, with CVs of 0.2 and 0.3 corresponding to resolutions of $55 \%$ and $85 \%$, respectively, with the same power.

The precision of the censuses carried out in our study was similar to figures presented previously (Fowler 1987; Greene and Alevizon 1989; Cheal and Thompson 1997; Thompson and Mapstone 1997; Samoilys and Carlos 2000; McClanahan et al. 2007). However, if judged against the benchmark of $\mathrm{CV} \leq 0.1$, a satisfactory result was achieved for only two species (Z. xanthurum and $N$. elegans). The most important source of variation in the census results was associated with short-term environmental oscillations, a finding in line with that of McClanahan et al. (2007). A perfect illustration of this source of error is represented by the results obtained for $A$. diadematus, which revealed high between-census variation. It appeared that $A$. diadematus reacted to the tidal state: at high tides the fish "hung" close to rocks and were easy to spot, but at low tides they mostly disappeared. As the biology of $A$. diadematus is poorly known, we can only speculate that they remained in the same places but hidden in crevices or coral rubble. However, environmental variation also strongly influenced the census results for three species of Chaetodontidae, a family known for its sedentary behavior (Pratchett et al. 2013). The assumption of the present work that fish detectability may vary markedly between censuses is also supported by a recent study conducted by Mallet and co-workers (2016), which demonstrated that activity in coral reef fishes exhibits a distinct pattern of changes linked to tidal state and diurnal rhythms.

Considering that we did not try to limit observer variance and even deliberately preserved it (see Methods), its influence on results was surprisingly small. It was most pronounced in counts of T. rueppellii and two Acanthuridae: N. elegans and A. sohal. In the case of T. rueppellii, for which the rule "only fish larger than $10 \mathrm{~cm}$ count" was adopted, the variation in results might have been caused by subjective body size estimation, a problem that is correctable through training (St. John et al. 1990; Edgar et al. 2004). The two species of Acanthuridae were represented by large and conspicuous fishes, which often ventured into reef-ponds on the shoreward side of the reef crest or even further on the reef flat. As these reef-ponds were difficult for the human observers to access, especially 
at low tides, the adoption of field-marked convenient channels through the reef crest and standardized routes for all census-takers would likely have decreased such variation in the results.

Chance variance in censuses conducted on coral reefs is a consequence of the occluded views of observers. Furthermore, the natural mobility of fishes is usually not limited to the transect belt. In the present study, although ANOVA revealed that chance variance influenced the results of censuses for all species, its relative importance compared to that of environmental and inter-observer variation seemed to be lower. One notable exception to this rule was $R$. assasi, for which chance contributed considerably to the results, producing a $\mathrm{CV}$ value of $250 \%$. This can likely be explained as a consequence of the correlation between the number of observed fish and the precision of density estimates. As the mean number of $R$. assasi was rather low, the census results converged to almost presence/absence surveys, producing lower precision. A similar effect has been reported in the results of visual censuses of groups of animals as varied as monkeys (Plumtre 2000), birds (Enemar et al. 1978) and fishes (Tessier et al. 2005; McClanahan et al. 2007).

Each source of unwanted variance in census results requires specific countermeasures. The influence of shortterm environmental variance might be offset by scheduling censuses under the same environmental settings (e.g. time of day, waving, tides, water temperature, etc.). The question thus arises as to what exact environmental factors are important for each studied species, which should then be the topic of another, purposely designed pilot study or, at least, subject to informed guessing based on the literature. In research relying on data obtained from spatially contiguous sites, variance due to environmental oscillations may be reduced by running censuses at the same moment on all plots (Tessier et al. 2005), and then analyzing the data in time blocks. Observer variance may be reduced by enforcing more rigorous rules on conducting censuses and training census-takers, which could be of particular importance in censusing fishes moving in large schools (Bell et al. 1985; Thompson and Mapstone 1997). Observer variance to a certain extent may also be controlled through study design. If research requires the acquisition of samples from spatially or temporally iso- lated sites, censuses should be conducted by the same teams of observers who take replicates at each site (Edgar et al. 2004). Chance variance can only be controlled statistically by mass replication. For example, Samoilys and Carlos (2000) recommended running more than 10 census replicates for the assessment of fish densities using visual counting methods.

\section{Acknowledgements}

This work was funded through the Council of Students' Scientific Societies, University of Wroclaw. We also thank Kinga Mielcarska for logistic support and two anonymous referees for comments on earlier version of this manuscript.

\section{Compliance}

The study was purely observational and no specimens were collected. All procedures were carried out in accordance with Egyptian law.

\section{References}

Bell JD, Craik GJS, Pollard DA, Russell BC (1985) Estimating length frequency distributions of large reef fish underwater. Coral Reefs 4: 41-44

Canty A, Ripley B (2015) boot: Bootstrap R (S-Plus) functions. $\mathrm{R}$ package version $1.3-17$

Cheal AJ, Thompson AA (1997) Comparing visual counts of coral reef fish: implications of transect width and species selection. Mar Ecol Prog Ser 158: 241-248

Davison AC, Hinkley DV (1997) Bootstrap methods and their applications. Cambridge University Press, Cambridge

Edgar GJ, Barrett NS, Morton AJ (2004) Biases associated with the use of underwater visual census techniques to quantify the density and size-structure of fish populations. J Exp Mar Bio Ecol 308: 269-290

Emslie MJ, Pratchett MS, Cheal AJ (2011) Effects of different disturbance types on butterflyfish communities of Australia's Great Barrier Reef. Coral Reefs 30: 461-471

Enemar A, Sjöstrand B, Svensson S (1978) The effect of ob- 
server variability on bird census results obtained by a territory mapping technique. Ornis Scand 9: 31-39

Fowler AJ (1987) The development of sampling strategies for population studies of coral reef fishes. A case study. Coral Reefs 6: 49-58

Greene LE, Alevizon WS (1989) Comparative accuracies of visual assessment methods for coral reef fishes. Bull Mar Sci 44: 899-912

Jennings S, Polunin NVC (1996) Effects of fishing effort and catch rate upon the structure and biomass of Fijian reef fish communities. J Appl Ecol 33: 400-412

Keast A, Harker J (1977) Strip counts as a means of determining densities and habitat utilization patterns in lake fishes. Environ Biol Fishes 1: 181-188

Mallet D, Vigliola L, Wantiez L, Pelletier D (2016) Diurnal temporal patterns of the diversity and the abundance of reef fishes in a branching coral patch in New Caledonia. Austral Ecol 41: 733-744

McClanahan TR, Arthur R (2001) The effect of marine reserves and habitat on populations of East African coral reef fishes. Ecol Appl 11: 559-569

McClanahan TR, Graham NAJ, Maina J, Chabanet P, Bruggemann JH, Polunin NVC (2007) Influence of instantaneous variation on estimates of coral reef fish populations and communities. Mar Ecol Prog Ser 340: 221-234

Plumptre AJ (2000) Monitoring mammal populations with line transect techniques in African forests. J Appl Ecol 37: 356-368
Pratchett MS, Chong-Seng KM, Feary DA, Hoey AS, Fulton CJ, Nowicki JP, Dewan AK, Walker SPW, Berumen ML (2013) Butterflyfishes as a model group for reef fish ecology: important and emerging research topics. In: Pratchett MS, Berumen ML, Kapoor BG (eds) Biology of butterflyfishes. CRC Press, Boca Raton, pp 310-334

R Core Team (2015) R: A language and environment for statistical computing. Vienna: R Foundation for Statistical Computing

Samoilys MA, Carlos G (2000) Determining methods of underwater visual census for estimating the abundance of coral reef fishes. Environ Biol Fishes 57: 289-304

St. John J, Russ GR, Gladstone W (1990) Accuracy and bias of visual estimats of numbers, size structure and biomass of a coral reef fish. Mar Ecol Prog Ser 64: 253-262

Tessier E, Chabanet P, Pothin K, Soria M, Lasserre G (2005) Visual censuses of tropical fish aggregations on artificial reefs: slate versus video recording techniques. J Exp Mar Bio Ecol 315: 17-30

Thompson AA, Mapstone BD (1997) Observer effects and training in underwater visual surveys of reef fishes. Mar Ecol Prog Ser 154: 53-63

Received: 15 February 2018 Accepted: 15 June 2018

(C) Japanese Coral Reef Society 